\title{
A Short Chain NAD(H)-Dependent Alcohol Dehydrogenase (HpSCADH) from Helicobacter Pylori: a Role in Growth under Neutral and Acidic Conditions.
}

\author{
A. Kumari \\ Technological University Dublin \\ Henry Windle \\ Trinity College Dublin \\ Denise Cornally \\ Technological University Dublin, denise.cornally@tudublin.ie
}

See next page for additional authors

Follow this and additional works at: https://arrow.tudublin.ie/ehsiart

Part of the Medicine and Health Sciences Commons

\section{Recommended Citation \\ doi:10.1016/j.biocel.2013.04.006 \\ This Article is brought to you for free and open access by the ESHI Publications at ARROW@TU Dublin. It has been accepted for inclusion in Articles by an authorized administrator of ARROW@TU Dublin. For more information, please contact arrow.admin@tudublin.ie, aisling.coyne@tudublin.ie,gerard.connolly@tudublin.ie.}

Alka,K., Windle, H., Cornally, D., Ryan, B.J., Henehan, G.T.M. (2013). A short chain NAD(H)-dependent alcohol dehydrogenase (HpSCADH) from Helicobacter pylori: a role in growth under neutral and acidic conditions. The International Journal of Biochemistry \& Cell Biology, vol.45, no.7, pp.1347-1355.

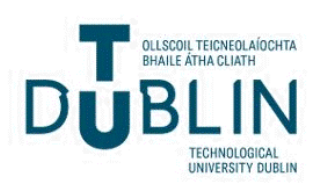




\section{Authors}

A. Kumari, Henry Windle, Denise Cornally, Barry Ryan, and Gary Henehan

This article is available at ARROW@TU Dublin: https://arrow.tudublin.ie/ehsiart/4 


\section{AUTHOR QUERY FORM}

\begin{tabular}{|c|c|c|}
\hline 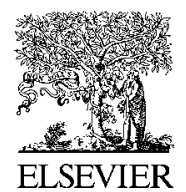 & Article Number: 3996 & $\begin{array}{l}\text { Please e-mail or fax your responses and any corrections to: } \\
\text { E-mail: corrections.eseo@elsevier.thomsondigital.com } \\
\text { Fax: }+35361709272\end{array}$ \\
\hline
\end{tabular}

Dear Author,

Please check your proof carefully and mark all corrections at the appropriate place in the proof (e.g., by using on-screen annotation in the PDF file) or compile them in a separate list. Note: if you opt to annotate the file with software other than Adobe Reader then please also highlight the appropriate place in the PDF file. To ensure fast publication of your paper please return your corrections within 48 hours.

For correction or revision of any artwork, please consult http://www.elsevier.com/artworkinstructions.

Any queries or remarks that have arisen during the processing of your manuscript are listed below and highlighted by flags in the proof. Click on the ' $\underline{Q}$ ' link to go to the location in the proof.

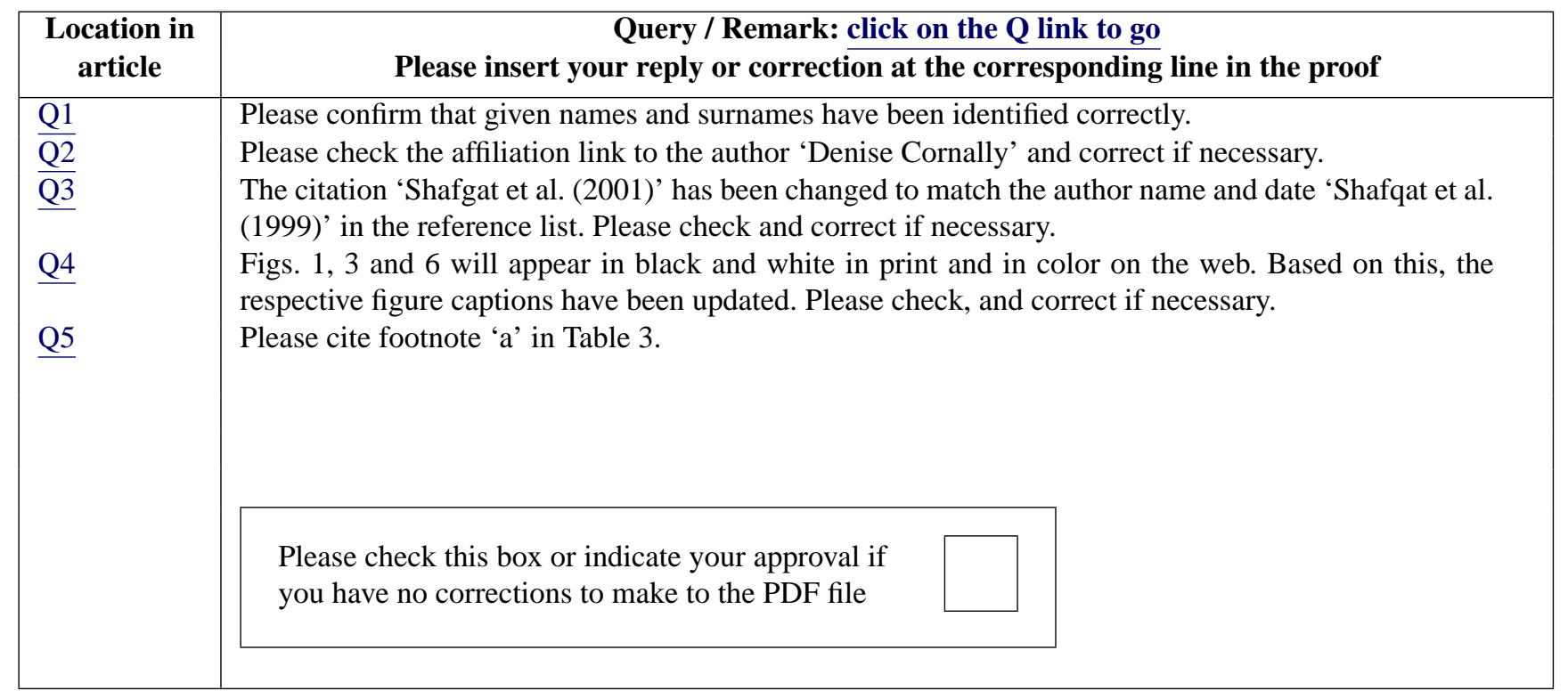

Thank you for your assistance. 


\title{
The International Journal of Biochemistry \& Cell Biology
}

\section{A short chain NAD $(\mathrm{H})$-dependent alcohol dehydrogenase (HpSCADH) from Helicobacter pylori: A role in growth under neutral and acidic conditions}

\author{
Q1 Kumari Alka ${ }_{\wedge}^{\mathrm{a}}$, Henry J. Windle ${ }_{\wedge}^{\mathrm{b}}$, Denise Cornally, ${ }_{\wedge}^{\mathrm{a}}$, Barry J. Ryan ${ }_{\wedge}^{\mathrm{a}}$, , Gary T.M. Henehan ${ }_{\wedge}^{\mathrm{a}, *}$ \\ Q2 a School of Food Science and Environmental Health, Dublin Institute of Technology (DIT), Marlborough Street, Dublin 1, Jreland \\ b Institute of Molecular Medicine, Trinity Centre for Health Sciences, St James's Hospital, Dublin 8, Ireland
}

A R T I C L E I N F O

\section{Article history:}

Received 12 November 2012

Received in revised form 27 March 2013

Accepted 3 April 2013

Available online $\mathrm{xxx}$

\section{Keywords:}

Alcohol dehydrogenase

Inhibition

Kinetics

Knockout

Mutant

Pyrazole

\begin{abstract}
A B S T R A C T
Toxic aldehydes produced by alcohol dehydrogenases have been implicated in the pathogenesis of Helicobacter pylori-related damage to the gastric mucosa. Despite this, the enzymes that might be responsible for producing such aldehydes have not been fully described. It was, therefore, of considerable interest to characterize the alcohol oxidizing enzymes in this pathogen. Previous work in this laboratory characterized two such $H$. pylori enzymes that had broad specificity for a range of aromatic alcohol substrates. An enzyme with broad specificity for aliphatic alcohols is likely to be required in order that $H$. pylori can metabolize the wide range of substrates encountered in the gastric mucosa. In this study we describe HpSCADH, an alcohol dehydrogenase from H. pylori 26695 with broad specificity for aliphatic alcohols. HpSCADH was classified in the cD1e subfamily of classical short chain alcohol dehydrogenases. The enzyme was a monomer of approximately $29 \mathrm{kDa}$ with a preference for $\mathrm{NAD}^{+}$as cofactor. Pyrazole was found to be a competitive inhibitor of HpSCADH.

The physiological role of this enzyme was explored by construction of an HpSCADH isogenic mutant. AtpH 7.0 the mutant showed reduced growth which became more pronounced when the pH was lowered to 5.0. When pyrazole was added to wild type $H$. pylori cells it caused growth profiles to be reduced to those of the isogenic mutant suggesting that HpSCADH inhibition alone was responsible for growth reduction. Taken together, the data relating to the alcohol metabolizing enzymes of this pathogen indicate that they play an important role in $H$. pylori growth and adaptation to acidic environments. The therapeutic potential of targeting $H$. pylori alcohol dehydrogenases is discussed.
\end{abstract}

(c) 2013 Published by Elsevier Ltd.

\section{Introduction}

Helicobacter pylori is implicated in the pathogenesis of gastric lymphoid tissue-associated B-cell lymphoma (Von Herbay et al., 1995) and gastric adenocarcinoma in humans (Parsonnet et al., 1991). Furthermore, 90-95\% of duodenal ulcers in Europe originate from $H$. pylori infection (Krah et al., 2004).

A role for aldehyde toxicity in the pathogenicity of $H$. pylorimediated gastric disease has been proposed. Specifically, it was suggested that alcohol dehydrogenases of $H$. pylori contribute its pathogenicity by oxidizing alcohols to produce toxic aldehydes: the aldehydes then react with and modify proteins in the gastric mucosa to cause inflammation. This inflammatory process may lead to gastric adenocarcinoma in some cases (Salmela et al., 1997; Homann et al., 1997; Salaspuro, 2003; Matysiak-Budnik et al., 1995;

\footnotetext{
* Corresponding author. Tel.: +353 1402 4408; fax: +3531 4024495

E-mail address: gary.henehan@dit.ie (G.T.M. Henehan).
}

Figura, 1997). Ethanol-derived acetaldehyde has been the focus of much of the concern for gastric carcinoma (Salaspuro, 2011).

This laboratory has undertaken a systematic study of the pyridine linked alcohol oxidizing enzymes of $H$. pylori. The annotated genome of H. pylori 26695 (Tomb et al., 1997) identifies analdo-keto reductase (HpAKR), a cinnamyl alcohol dehydrogenase (HpCAD) and a putative short chain alcohol dehydrogenasegene (HpSCADH). These pyridine linked oxidoreductases might all be expected to play a role in alcohol oxidation. Two of these enzymes (HpCAD and HpAKR) have been extensively studied in this laboratory (Mee et al., 2005; Cornally et al., 2008). Both HpCAD and HpAKR showed broad substrate specificity for aromatic alcohols. Interestingly, HpAKR was shown to play an important role in the growth of $H$. pylori under acidic conditions and is thought to be involved in the adaptation of this bacterium to growth in the gastric mucosa (Cornally et al., 2008). An enzyme with specificity for aliphatic alcohols is presumably necessary to allow this bacterium to catalyze the oxidation of a wider range of physiological substrates.

This study identifies an enzyme capable of oxidizing aliphatic alcohols which provides the organism with the ability to 
metabolize a broad range of aliphatic and aromatic substrates. The physiological role of this dehydrogenase was of considerable interest since it appeared to be the dominant enzyme in the metabolism of non-aromatic alcohols in the organism. To explore this issue further an isogenic HpSCADH-negative mutant of $H$. pylori, was constructed using insertional mutagenesis. The mutant showed reduced growth compared to the wild type at both neutral and acidic $\mathrm{pH}$ indicating a role for this dehydrogenase in adaptation to the gastric mucosa. We identify pyrazole as an inhibitor of this enzyme and show that this compound can reduce the growth of H. pylori in culture.

\section{Materials and methods}

\subsection{Cloning of the HPSCADH gene}

All DNA manipulations were performed as described previously (Sambrook and Maniatis, 1989). Oligonucleotides used for PCR amplification of the HpSCADH gene, using $H$. pylori 26695 genomic DNA as template, were designed using the putative short chain alcohol dehydrogenase gene sequence from $H_{\wedge}$ pylori 26695, available at the NCBI database (NP_207155.1). The forward (5'-CGCCATATGGCGCACATT- $\left.3^{\prime}\right)$ and the reverse ( $5^{\prime}$ CGCGGATCCAGGGTTTTT ATG GGTG-3') primers were designed to introduce $N d e$ I and $B a m H$ I restriction enzyme cleavage sites at the $\mathrm{N}$-terminus and C-terminus, respectively. Polymerase Chain Reactions were performed using a Perkin-Elmer 2400 thermal cycler with Taq DNA polymerase (Boerhinger Mannheim, Germany). Primers were obtained from Sigma-Genosys (UK). For standard amplifications approximately $100 \mathrm{ng}$ of template DNA was mixed with 5 pmol of each specific primer in a reaction volume of $25 \mu \mathrm{l}$. Reactions were performed by denaturing DNA at $94^{\circ} \mathrm{C}$ for $2 \mathrm{~min}$ 15 s, annealing at $45^{\circ} \mathrm{C}$ for 30 s and extension at $72^{\circ} \mathrm{C}$ for 45 s. A total of 30 cycles were performed. The amplified PCR product was cloned into pET16(b) (Novagen). The resulting construct was named pETHpSCADH. The positive clones were confirmed by DNA sequencing (Eurofins MWG, Ebensburg, Germany).

\subsection{Purification of the HpSCADH gene product}

Escherichia coli BL21 (DE3) plysS transformed with the pET16(b)$\mathrm{HpSCADH}$ construct were grown at $37^{\circ} \mathrm{C}$ in LB medium containing $50 \mu \mathrm{g} / \mathrm{ml}$ ampicillin. At an $\mathrm{OD}_{600}$ of 0.8 the expression of $\mathrm{HpSCADH}$ was induced by the addition of $1.0 \mathrm{mM}$ IPTG at $25^{\circ} \mathrm{C}$ and incubated for $14 \mathrm{~h}$ with constant shaking $(280 \mathrm{rpm})$. Cells were harvested and resuspended in lysis buffer ( $20 \mathrm{mM}$ Tris- $\mathrm{HCl}$, pH 7.9, 5 mM imidazole, $200 \mathrm{mM} \mathrm{NaCl}$ ) and lysed by sonication for 130 s on ice (VC-750 ultrasound generator, Sonics and Materials Inc.). Cell debris was collected by centrifugation and the supernatant was applied to a nickel-charged iminodiacetic acid column (Novagen) equilibrated with lysis buffer. The $\mathrm{Ni}^{+}$column was washed with 21 of wash buffer, which was the same as the lysis buffer before elution with $20 \mathrm{mM}$ Tris- $\mathrm{HCl}$ (pH 7.9) containing $200 \mathrm{mM} \mathrm{NaCl}$ and $300 \mathrm{mM}$ imidazole. Fractions containing purified recombinant HpSCADH were identified by SDS-polyacrylamide gel electrophoresis. Positive fractions were pooled and dialyzed against 21 of pre-chilled $0.2 \mathrm{M}$ potassium phosphate, $\mathrm{pH} 7.4$, for $36 \mathrm{~h}$ with three changes.

\subsection{Enzyme assay}

Kinetic parameters were determined spectrophotometrically at $37^{\circ} \mathrm{C}$ using an Agilent 8453 diode array spectrophotometer (Agilent Technologies, Palo Alto, CA, USA). The purified HpSCADH was assayed for both the oxidation of alcohols (forward reaction) and the reduction of aldehydes (reverse reaction). Activities with alcohols were measured in a final volume of $2.0 \mathrm{ml}$ in $0.2 \mathrm{M}$ potassium phosphate buffer ( $\mathrm{pH} 7.5$ ) containing $0.2 \mathrm{mM} \mathrm{NAD}^{+}$and alcohol substrate, typically $50 \mathrm{mM}$ for ethanol. The formation of NADH at $340 \mathrm{~nm}$ was followed. The molar extinction coefficient $(\varepsilon)$ used ( $\mathrm{pH}$ 7.5) was $\varepsilon_{340}=6220 \mathrm{M}^{-1} \mathrm{~cm}^{-1}$ for NADH. The oxidation of cinnamyl alcohol or reduction of cinnamaldehyde was monitored at $366 \mathrm{~nm}$ (Larroy et al., 2003). Steady-state parameters were determined by fitting initial rates to the Michaelis-Menten equation using ENZFITTER (Elsevier Biosoft, Cambridge, UK).

Activities towards different aldehydes were assayed in a $2 \mathrm{ml}$ reaction mixture containing $0.2 \mathrm{M}$ potassium phosphate buffer $(\mathrm{pH}$ 7.5 ) with $0.2 \mathrm{mM}$ NADH and varying aldehyde concentrations. The decrease in NADH absorbance at $340 \mathrm{~nm}$ was followed to measure enzyme activity.

\subsection{Effect of $\mathrm{pH}$ and temperature on HpSCADH activity}

The optimum $\mathrm{pH}$ for HpSCADH activity was determined in a $2 \mathrm{ml}$ assay mixture containing $0.2 \mathrm{mM} \mathrm{NADH} / \mathrm{NAD}^{+}$and $1 \mathrm{mM}$ propionaldehyde/50 mM 1-propanol as substrates for the reduction and oxidation half reactions respectively, in a standard assay mixture at $37^{\circ} \mathrm{C}$. Different $\mathrm{pH}$ values were generated using the following buffers: $\mathrm{pH} 4-5$ : $50 \mathrm{mM}$ sodium citrate, $\mathrm{pH}$ 6-8: $50 \mathrm{mM}$ potassium phosphate and $\mathrm{pH}$, $-10: 50 \mathrm{mM}$ glycine.

To examine the effect of temperature, HpSCADH was assayed in the temperature range $20-60{ }^{\circ} \mathrm{C}$ in a $2 \mathrm{ml}$ assay mixture containing $0.2 \mathrm{mM} \mathrm{NAD}^{+}, 50 \mathrm{mM}$ of 1-propanol as substrate and $\sim 11 \mu \mathrm{g}$ of HpSCADH ml ${ }^{-1}$ of assay mixture. The activity at various temperatures was studied by incubating the enzyme in $0.2 \mathrm{M}$ potassium phosphate buffer ( $\mathrm{pH} \mathrm{7.5)}$ at different temperatures for $30 \mathrm{~min}$. Each sample was then assayed for residual activity.

\subsection{Bacterial strains and plasmids}

H. pylori strains 26695 and 1061 were originally obtained from A. Van Vliet and J. Kusters (Erasmus MC University Medical Centre, Rotterdam, The Netherlands). The wild type strains were maintained on Columbia Blood Agar plates containing 5\% $(\mathrm{v} / \mathrm{v})$ defibrinated horse blood while the medium for the HPSCADH mutant was supplemented with kanamycin $(20 \mu \mathrm{g} / \mathrm{ml})$ for selection. Plates were incubated in a microaerophilic-humidified atmosphere generated using a MART Anoxomat system (Lichtenvoorde, the Netherlands). For liquid culture, strains were grown in Brucella Broth (Sigma) supplemented with $7 \%(\mathrm{v} / \mathrm{v})$ foetal calf serum. Cultures were grown in $25 \mathrm{~cm}^{2}$ cell culture flasks with constant shaking ( $120 \mathrm{rpm}$ ) at $37^{\circ} \mathrm{C}$ in an orbital incubator shaker.

An acidic environment was created using Brucella broth which was adjusted to the desired $\mathrm{pH}$ using $0.1 \mathrm{M} \mathrm{HCl}$ (after the addition of foetal calf serum) and subsequently filter sterilized. E. coli was grown in LB broth and on LB agar, as required. The antibiotics used for selection purposes were ampicillin $(50 \mu \mathrm{g} / \mathrm{ml})$ and kanamycin $(20 \mu \mathrm{g} / \mathrm{ml})$.

\subsection{DNA manipulations}

All DNA manipulations were carried out according to standard procedures (Sambrook and Maniatis, 1989). Transformation of E. coli cloning host (DH5 $\alpha$; Invitrogen) was performed according to the manufacturer's protocol. Natural transformation of $H$. pylori with plasmid constructs was carried out as described in Smeets et al. (2000). All oligonucleotide primers were obtained from Eurofins MWG (Ebensburg, Germany).

\subsection{Construction of HpSCADH jisogenic mutant}

The HpSCADH gene was inactivated in $H$. pylori strain 1061 by gene disruption. The purified PCR-amplified Hp0357 (HpSCADH 


HPSCADH
HPHPAG1
HPB128
HPHPKX_438
HPR12
HP52
HP51
HPB38
HPG27
HPJ99

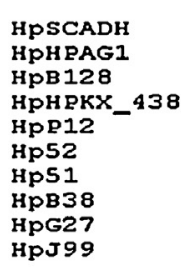

HPSCADH
HPHPAG1
HPB128
HPHPKX_438
HPP12
HP52
HP51
HPB38
HPG27
HPJ99

\begin{tabular}{|c|c|c|c|c|c|c|}
\hline & & & 240 & * & & \\
\hline HPSCADH & : & I & QTEADLPTHF & N P- - - & : & 240 \\
\hline НРНRAG1 & : & & OTEAPLPTH: & K $\mathrm{P}---$ & : & 2 \\
\hline НрВ128 & : & $E I$ & QTEAPLPTH & S P-- - & : & \\
\hline HPHPKX_438 & : & --- & $------n---1$ & ------ & : & - \\
\hline HрP12 & : & $M E I$ & SQTEAPLPTH & NH--- & : & 250 \\
\hline Hp52 & : & $I$ & QTEAPLPTH: & NP --- & : & 250 \\
\hline Hp51 & 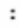 & & SQTEAPLPTH: & NH--- & : & 250 \\
\hline pB38 & & $T$ & QTEAPLPTH: & NP--- & : & 250 \\
\hline pG27 & & T & QTEADLPTH: & ILKGE & : & 253 \\
\hline 1pJ99 & e & 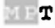 & SOTEAPLPTH: & NR--- & : & 250 \\
\hline
\end{tabular}

mp sqtfaplpthk
20
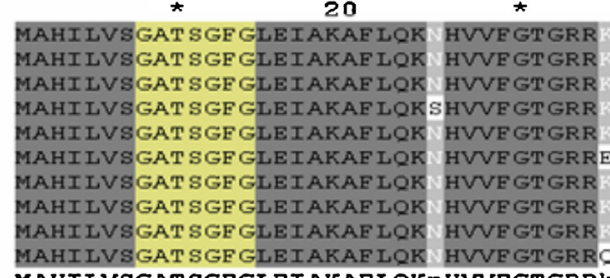

40
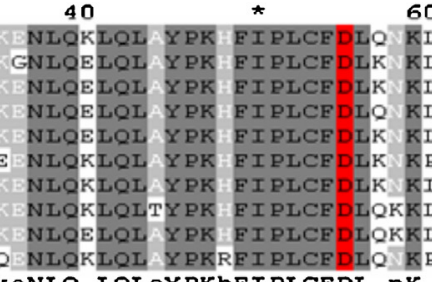

60
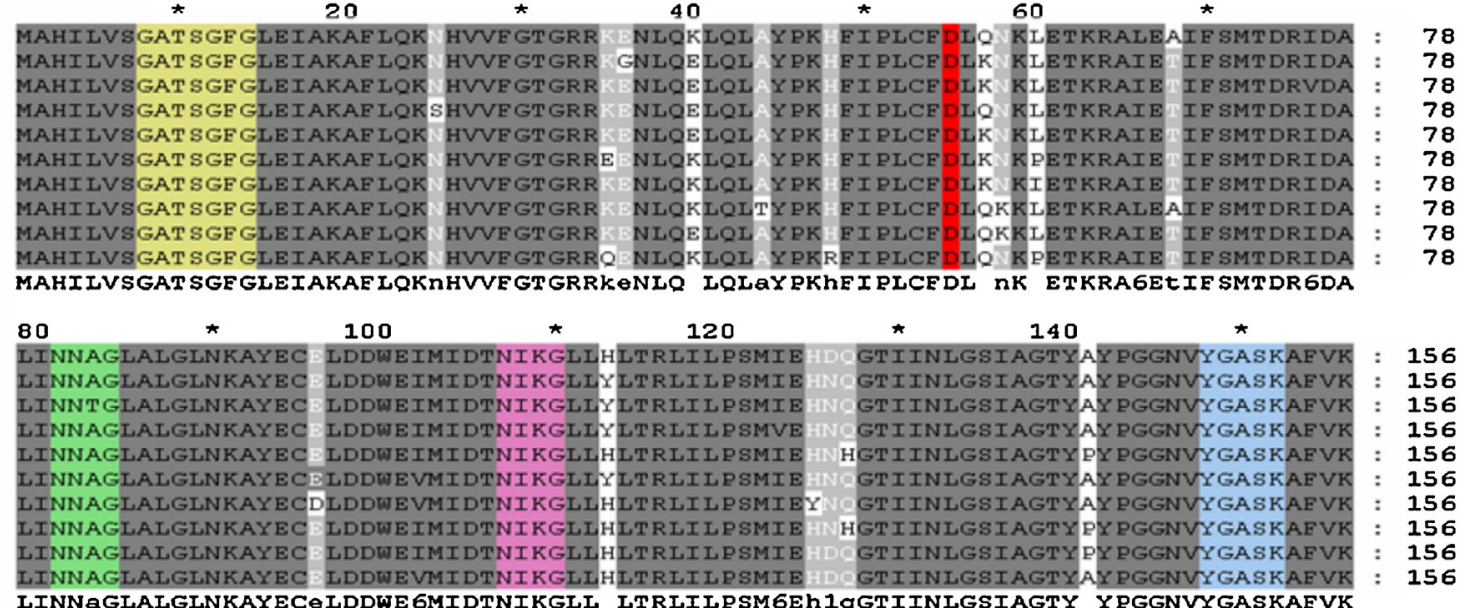

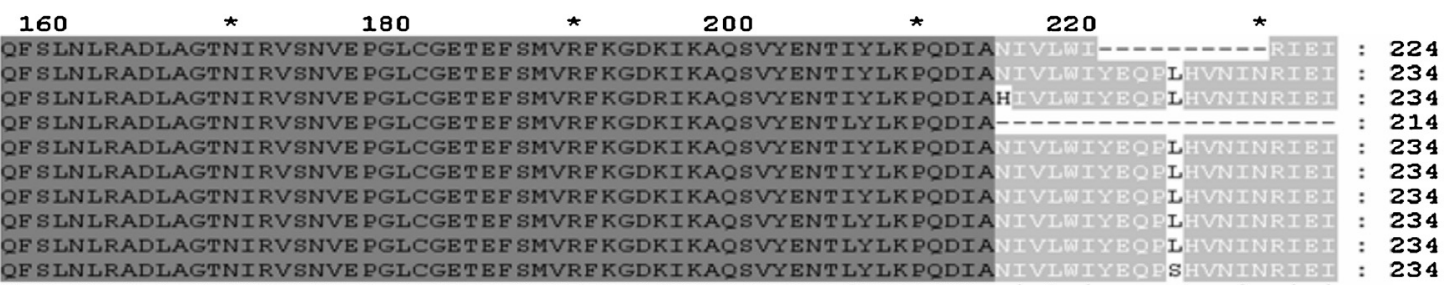

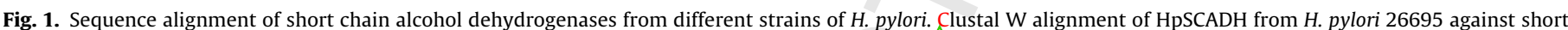

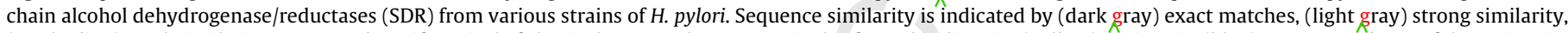

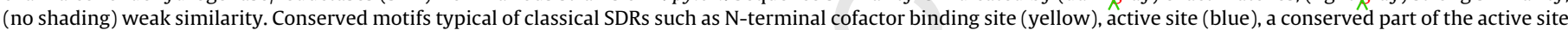

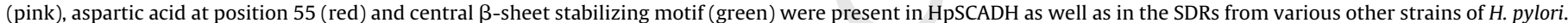

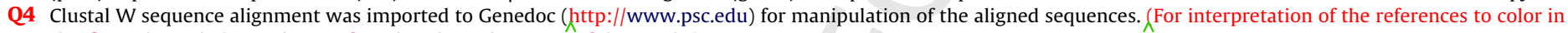
this figure legend, the reader is referred to the web version of the article.)

gene) was ligated into the cloning vector pGEM-T Easy (Promega) by TA cloning and transformed into $E$. coli $\mathrm{DH} 5 \alpha$. The primers used to amplify $\mathrm{Hp} 0357$ were: ${ }^{\prime}$-ATGGCGCACATTTTAGTTAGCGG$3^{\prime}$ as the forward primer and $5^{\prime}$-AGGGTTTTTATGGGTGGGTAG-3' as the reverse primer. A $1.5-\mathrm{kb}$ PCR product from plasmid pJMK30 containing a gene encoding resistance to kanamycin was amplified using $5^{\prime}$-TGATCAGTAAAACGACGGCCAGT-3' as forward primer and $5^{\prime}$-TGATCAAACAGCTATGACCATG ${ }^{-3}{ }^{\prime}$ as reverse primer. The PCR amplified kanamycin cassette (aphA-3) containing the unique $\mathrm{Bcl}$ I site at both ends was subcloned into pGEM-T Easy vector (Promega) by TA cloning and transformed into E. coli DH5 $\alpha$ (Invitrogen). Plasmid DNA isolated from dam ${ }^{+}$E. coli (e.g. DH5 $\alpha$ ) is completely resistant to cleavage by $B c l$, , which cleaves at GATC sites. These sites are blocked by dam methylation (methylation at the $\mathrm{N}^{6}$ position of the adenine in the sequence $5^{\prime}$-GATC- $3^{\prime}$ ). This was circumvented by transforming the pGEM:HpSCADH and pGEM:aphA-3 constructs into a dam^- $/ \mathrm{dcm}^{-}$strain of E. coli (New England Biolabs, Herts, England).

Both pGEM:Hp0357 and pGEM:aphA-3 (isolated from $\mathrm{dam}^{-} / \mathrm{dcm}^{-}$E. coli) were digested with $\mathrm{Bcl}$ I to generate cohesive ends. The $\mathrm{Bcl}$ I digested kanamycin cassette was cloned into the unique $B c l$ I site within the coding region of HpSCADH gene yielding pGEM:HpSCADH::aphA-3 construct (Fig. 5). Disruption of the HpSCADH gene by the kanamycin cassette was confirmed by DNA sequencing (Eurofins MWG, Ebensburg, Germany). The mutant construct was used for natural transformation of $H$. pylori 1061. H. pylori genomic DNA was purified using the Wizard ${ }^{\circledR}$ Genomic DNA Purification Kit (Promega, USA).

\section{Results}

\subsection{Sequence analysis/classification}

A protein BLAST analysis of HpSCADH revealed the highest sequence similarity with a number of putative short chain alcohol dehydrogenases and oxidoreductases from pathogens belonging to various bacterial families such as Actinobacillus pleuropneumoniae (ZP_00134882.2, 63\% identity), Aggregatibacter actinomycetemcomitans (YP_003255986.1, 63\% identity), Mannheimia haemolytica (ZP_05988835.1,61\% identity), Aeromonas hydrophila (YP_855033.1, 60\% identity), Haemophilus influenzae (ZP_04466822.1, 58\% identity) and Streptococcus mutans NN2025 (YP_003484911.1, 57\% identity).

Clustal $\mathrm{W}$ sequence alignment of HpSCADHs across various strains of $H$. pylori shows several conserved motifs (Fig. 1). These motifs include an N-terminal cofactor binding site (GxxxGxG, yellow), the active site motif (YxxxK, blue) and a mid-region conserved site (NNAG, green) (Jornvall et al., 1999; Van der Oost et al., 2001;
197
198
199
200

201

202

203

204

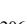

207 


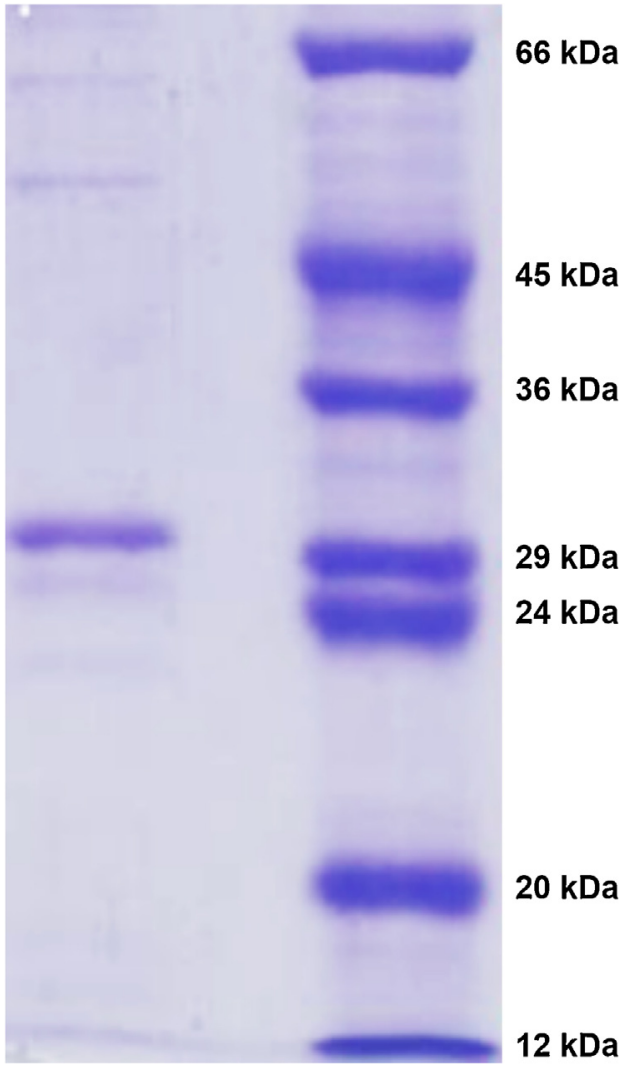

Fig. 2. SDS-PAGE of purified HpSCADH. (Lane 1) from left: purified HpSCADH protein with an approximate molecular mass of $29 \mathrm{kDa}$. (Lane 2) protein standard marker proteins with molecular weight marked on right.

Kallberg et al., 2002). Based on these observations HpSCADH can be classified as a classical short chain alcohol dehydrogenase. An additional conserved motif (NhxG, pink, Fig. 1), which is involved in positioning the active site lysine residue and forming part of a postulated proton relay (Filling et al., 2002), is typical of classical SCADHs as is the presence of an aspartic acid at position 55 as part of the cofactor binding site (Fig. 1, red). The size of HpSCADH (250 amino acid residues) is also characteristic of classical SCADHs (Kallberg et al., 2002).

NADH-preferring classical SDRs have an acidic residue at the $\mathrm{C}$ terminal of the 2nd beta-strand (key position 36) (Wierenga et al., 1985,1986 ) unlike NADPH binding enzymes that have two basic residues (Tanaka et al., 1996). The HpSCADH sequence contains a glutamic acid at position 36 (Fig. 1) indicating that it is expected to show a preference for NADH over NADPH. Hence, HpSCADH belongs to the cD1e subfamily of the classical $\mathrm{NAD}(\mathrm{H})$-preferring SDRs.

\subsection{Expression and purification of $\mathrm{HpSCADH}$}

The recombinant HpSCADH was expressed with an N-terminal His-tag. Following purification and dialysis HpSCADH was stored in $0.2 \mathrm{M}$ phosphate buffer ( $\mathrm{pH} 7.5$ ) at $-20^{\circ} \mathrm{C}$. No loss of enzyme activity was observed when stored under these conditions for more than 1 month. Typically, 1 l of culture yielded $\sim 5 \mathrm{mg}$ of purified HpSCADH. The HpSCADH eluted from the Ni-column was $\sim 95 \%$ pure as shown by $12 \%$ SDS-polyacrylamide electrophoresis gels with a relative molecular mass of $\sim 29 \mathrm{kDa}$ (Fig. 2). Control activity measurements with E. coli BL21 (DE3) plysS cell extracts lacking the HpSCADH construct showed no short chain alcohol dehydrogenase activity.

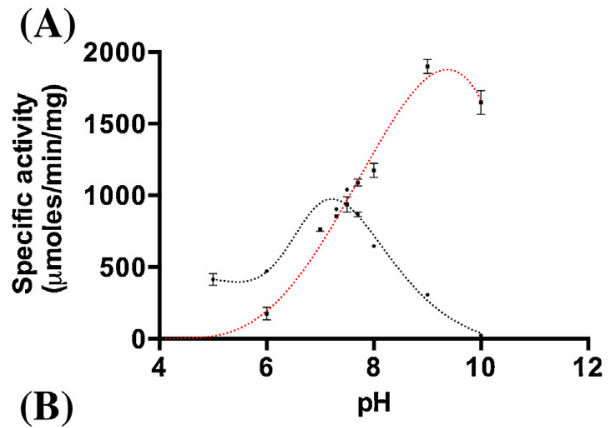

(B)

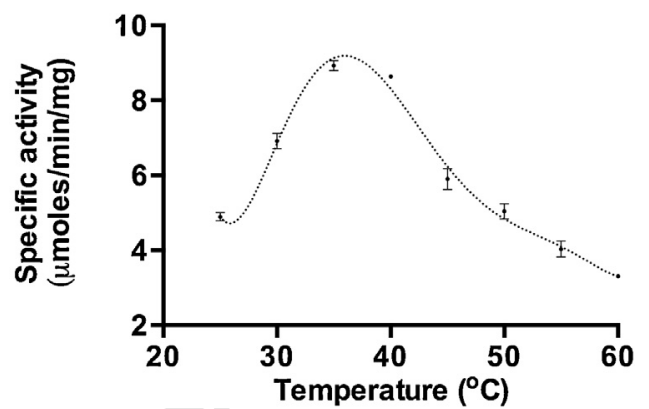

Fig. 3. Characterization of HPSCADH: (A) HpSCADH activity as a function of pH for the oxidation (red) and reduction (black) half reactions. The buffers used were as follows: $\mathrm{pH}$ 4-5: $0.2 \mathrm{M}$ sodium citrate, $\mathrm{pH}$ 6-8: $0.2 \mathrm{M}$ potassium phosphate and $\mathrm{pH}$ 9-10: $0.2 \mathrm{M}$ glycine. Assays were carried out at $37^{\circ} \mathrm{C}$ as described in Section 2. The assay mixture for the oxidation reaction contained $50 \mathrm{mM}$ 1-propanol while for reduction $1 \mathrm{mM}$ propionaldehyde was used as substrate. (B) Temperature dependence of HpSCADH activity. Initial rates of HpSCADH mediated oxidation of ethanol $(50 \mathrm{mM})$ over a range of temperatures. Activity was measured using standard conditions, as outlined in Section 2. (For interpretation of the references to color in this figure legend, the reader is referred to the web version of the article.)

\subsection{Characterization: optimum $\mathrm{pH}$ and temperature}

The activity of HpSCADH was dependent on $\mathrm{pH}$ for both the reduction and oxidation half reactions (Fig. $3 \mathrm{~A}$ ). In the reduction reaction there was a narrow peak of maximum activity at approximately $\mathrm{pH}$ 7.5. The oxidation reaction showed less marked dependence in the $\mathrm{pH}$ range of $7-9$ with a broad peak centred around $\mathrm{pH} 9$ (Fig. 3A).

The effect of temperature on HpSCADH activity is shown in Fig. 3B. The reaction rate increases up to about $38^{\circ} \mathrm{C}$ and then decreases rapidly. The optimum range was $35-40^{\circ} \mathrm{C}$. All experiments were carried out in triplicate.

\subsection{Substrate specificity}

HpSCADH showed no activity with $\operatorname{NADP}(H)$. Its activity was tested with a range of aliphatic and aromatic alcohol/aldehydes, ketones and dicarbonyls (Tables $1 \mathrm{~A}$ and $1 \mathrm{~B}$ ). Steady-state parameters were determined for the most active substrates (Table 2). All assays were carried out at $\mathrm{pH} 7.5$, and at $37^{\circ} \mathrm{C}$.

Greatest catalytic efficiency with respect to the alcohol substrates tested was seen with 1-propanol which had a $k_{\text {cat }} / k_{\mathrm{m}}$ value of $118.4 \mathrm{~s}^{-1} \mathrm{mM}^{-1}$. The enzyme showed no activity with aromatic alcohols except for a discrete activity with cinnamyl alcohol. Of the aldehydes evaluated as substrates, butyraldehyde and cinnamaldehyde yielded $k_{\text {cat }} / k_{\mathrm{m}}$ values of $29,198 \mathrm{~s}^{-1} \mathrm{mM}^{-1}$ and $540 \mathrm{~s}^{-1} \mathrm{mM}^{-1}$ respectively. Some activity was seen with pyridine aldehydes.

The effect of branched chain alcohol substrates on HpSCADH activity was explored by comparing primary, secondary and tertiary butanol. It was found that HpSCADH catalyzed the oxidation of 1 -butanol at a rate that was 1.5 -fold greater than 2-butanol 
Table 1A

Substrate screening of the $H$. pylori HpSCADH catalyzed oxidation of alcohols.

\begin{tabular}{lll}
\hline Substrate & $\begin{array}{l}\text { Substrate } \\
\text { concentration }(\mathrm{mM})\end{array}$ & $\begin{array}{l}\text { Enzyme activity } \\
(\mu \mathrm{mol} / \mathrm{min} / \mathrm{mg})\end{array}$ \\
\hline Aliphatic alcohols & & \\
Methanol & 50 & $\mathrm{NDA}$ \\
Ethanol & 50 & 63.2 \\
1-Propanol & 50 & 625.5 \\
2-Propanol & 50 & 110.4 \\
1,2-Propandiol & 50 & $\mathrm{NDA}$ \\
1-Butanol & 50 & 79.5 \\
2-Butanol & 50 & 54.1 \\
Tert-butanol & 50 & $\mathrm{NDA}$ \\
2-Methyl-1-butanol & 50 & $\mathrm{NDA}$ \\
1-Pentanol & 50 & 270 \\
2-Pentanol & 10 & $\mathrm{NDA}$ \\
4-Penten-1-ol & 10 & $\mathrm{NDA}$ \\
Hexanol & 50 & 146.9 \\
Octanol & 10 & NDA \\
Aromatic alcohols & & \\
Benzyl alcohol & 10 & $\mathrm{NDA}$ \\
4-Methoxybenzylalcohol & 10 & $\mathrm{NDA}$ \\
4-Nitrobenzyl alcohol & 10 & NDA \\
Cyclohexanol & 50 & NDA \\
Cinnamylalcohol & 10 & 865.1 \\
Dicarbonyls & & \\
Phenylglyoxal & 1 & 94.2 \\
Methylglyoxal & 1 & 155.4 \\
\hline
\end{tabular}

$0.2 \mathrm{mM}$ of $\mathrm{NAD}^{+}$was used in all assay mixture. The dicarbonyl substrates were dissolved in $100 \%$ methoxyethanol. All alcohol substrates were dissolved in $0.2 \mathrm{M}$ phosphate buffer ( $\mathrm{pH} 7.5$ ) except hexanol and octanol which were dissolved in $100 \%$ methoxyethanol. NDA is no detectable activity.

while no detectable activity was observed with tertiary butanol. Thus, it was clear that the degree of branching strongly influenced catalysis with straight chain aliphatic substrates being optimal. Other aromatic alcohols, aldehydes and ketones showed no detectable activity (Tables $1 \mathrm{~A}$ and $1 \mathrm{~B}$ ). Among the dicarbonyls tested HpSCADH showed higher activity towards methylglyoxal than phenylglyoxal.

Table 1B

Substrate screening of the $H$. pylori HpSCADH catalyzed reduction of aldehydes.

\begin{tabular}{lll}
\hline Substrate & $\begin{array}{l}\text { Substrate } \\
\text { concentration }(\mathrm{mM})\end{array}$ & $\begin{array}{l}\text { Enzyme activity } \\
(\mu \mathrm{mol} / \mathrm{min} / \mathrm{mg})\end{array}$ \\
\hline $\begin{array}{l}\text { Aliphatic aldehydes } \\
\text { Formaldehyde }\end{array}$ & 1 & $\mathrm{NDA}$ \\
Acetaldehyde & 1 & 272.9 \\
Butyraldehyde & 0.1 & 575.6 \\
2-Methylbutyraldehyde & 1 & $\mathrm{NDA}$ \\
Propionaldehyde & 0.1 & 556.9 \\
Valeraldehyde & 1 & 277.9 \\
Hexanal & 1 & 371.5 \\
Octanal & 1 & 1342.2 \\
Crotanaldehyde & 1 & 834.5 \\
Glyceraldehyde & 1 & $\mathrm{NDA}$ \\
Aromatic aldehydes & & \\
Cinnamaldehyde & 0.5 & 509.8 \\
Pyridine 2 aldehyde & 1 & 688.8 \\
Pyridine 4 aldehyde & 1 & 135.6 \\
Benzaldehyde & 1 & $\mathrm{NDA}$ \\
Ketones & & $\mathrm{NDA}$ \\
Acetone & 50 & $\mathrm{NDA}$ \\
Propanone & 50 & $\mathrm{NDA}$ \\
Butanone & 50 & $\mathrm{NDA}$ \\
Pentanone & 50 & $\mathrm{NDA}$ \\
Acetophenone & 1 & $\mathrm{NDA}$ \\
2,2,2-Trifluroacetophenone & 1 & \\
Cyclohexanone & 10 & \\
\hline
\end{tabular}

$0.2 \mathrm{mM}$ of $\mathrm{NADH}$ was used in all assay mixture. All aldehyde and ketone substrates were dissolved in $100 \%$ methoxyethanol. NDA is no detectable activity. Methoxyethanol was not a substrate under these conditions.
Table 2

HpSCADH substrate specificity. Kinetic parameters of HpSCADH from $H$. pylori. All data are mean of triplicate measurements. Assays were carried out as described in Section 2.

\begin{tabular}{lccc}
\hline Substrate & \multicolumn{1}{l}{$k_{\mathrm{m}}(\mathrm{mM})$} & $k_{\text {cat }}\left(\mathrm{s}^{-1}\right)$ & $k_{\text {cat }} / k_{\mathrm{m}}\left(\mathrm{s}^{-1} \mathrm{mM}^{-1}\right)$ \\
\hline $\mathrm{NADH}^{\mathrm{a}}$ & $0.026 \pm 0.0043$ & $362.2 \pm 15.4$ & 13932.6 \\
$\mathrm{NAD}^{\mathrm{a}}$ & $0.036 \pm 0.007$ & $510.8 \pm 26.6$ & 14187.5 \\
Acetaldehyde & $1.2 \pm 0.61$ & $44.0 \pm 11.7$ & 52.8 \\
Butyraldehyde & $0.0036 \pm 0.0003$ & $105.1 \pm 1.5$ & 29198.0 \\
Propionaldehyde & $0.18 \pm 0.002$ & $86.9 \pm 1.9$ & 482.7 \\
Valeraldehyde & $1.07 \pm 0.39$ & $47.9 \pm 9.4$ & 44.8 \\
Hexanal & $0.99 \pm 0.11$ & $63.8 \pm 5.6$ & 64.4 \\
Cinnamaldehyde & $0.3 \pm .06$ & $162.0 \pm 14.9$ & 540.0 \\
Ethanol & $7.2 \pm 0.67$ & $3.0 \pm 0.1$ & 0.4 \\
1-Butanol & $3.1 \pm 0.30$ & $2.7 \pm 0.1$ & 0.9 \\
1-Propanol & $1.8 \pm 0.25$ & $213.1 \pm 5.6$ & 118.4 \\
2-Propanol & $280.93 \pm 73.85$ & $310.1 \pm 43.5$ & 1.1 \\
1-Pentanol & $12.9 \pm 1.11$ & $104.8 \pm 2.4$ & 8.1 \\
\hline
\end{tabular}

a Substrate used for the determination of the kinetic constants of NADH and NAD ${ }^{+}$ was $1 \mathrm{mM}$ butyraldehyde and $50 \mathrm{mM}$ ethanol respectively.

Table 3

Effectors of HpSCADH activity.

\begin{tabular}{llc}
\hline Compound & Concentration $(\mathrm{mM})$ & Relative activity $(\%)$ \\
\hline Pyrazole & 0.1 & 0 \\
Sodium valproate & 1 & 46 \\
Chloral hydrate & 1 & 100 \\
2-Mercaptoethanol & 1 & 100 \\
EDTA & 1 & 78 \\
$\mathrm{ZnSO}_{4}$ 只 & 1 & 70 \\
$\mathrm{MgCl}_{2}$ & 1 & 100 \\
$\mathrm{KCl}$ & 1 & 90 \\
\hline
\end{tabular}

a HpSCADH mediated oxidation of $1 \mathrm{mM}$ 1-butanol in a standard assay mixture was assumed to be the control at $100 \%$. The activity in the presence of various compound are expressed as the percentage of 1-butanol oxidase activity.

$\wedge$ Initial stock solutions of these compound were prepared in DMSO. All assays were carried out as described in Section 2. Data are mean of triplicate measurements.

\subsection{Inhibition studies}

The influence of various effector molecules on HpSCADH activity is summarized in Table 3. The presence of $\mathrm{Mg}^{2+}$ and $\mathrm{K}^{+}$had no significant effect on $\mathrm{HpSCADH}$ activity while $\mathrm{ZnSO}_{4}{ }^{1}$ showed mild inhibition. EDTA at $1 \mathrm{mM}$ concentration reduced the enzyme activity by $\sim 22 \%$. Sodium valproate, a potent inhibitor of manyaldoketo reductases (Hinshelwood et al., 2002; Kuhn et al., 1995; Todaka et al., 2000), was found to inhibit HpSCADH activity by $55 \%$ at a concentration of $1 \mathrm{mM}$ with little further inhibition seen at elevated concentrations. Chloral hydrate showed no inhibition. Treatment with 2-mercaptoethanol had no effect on the enzyme.

Pyrazole is a known potent inhibitor of many alcohol dehydrogenases with $K_{i}$ values typically in the low micromolar region (Goldberg and Rydberg, 1969; Li and Theorell, 1969; Reynier, 1969). HpSCADH activity was found to be fully inhibited by $100 \mu \mathrm{M}$ pyrazole (Table 3). Inhibition was of a competitive-type with respect to 1 -butanol (Fig. 4) and a $K_{i}$ of $10.05 \pm 0.03 \mu \mathrm{M}$ was estimated.

\subsection{Disruption of HpSCADH by insertional mutagenesis and characterization of the isogenic mutant}

HpSCADH was markedly specific for aliphatic alcohols which made it interesting to evaluate its role in alcohol and aldehyde

\footnotetext{
1 Initial stock solutions of these compounds were prepared in DMSO. All assays were carried out as described in Section 2. Data are mean of triplicate measurements.
} 


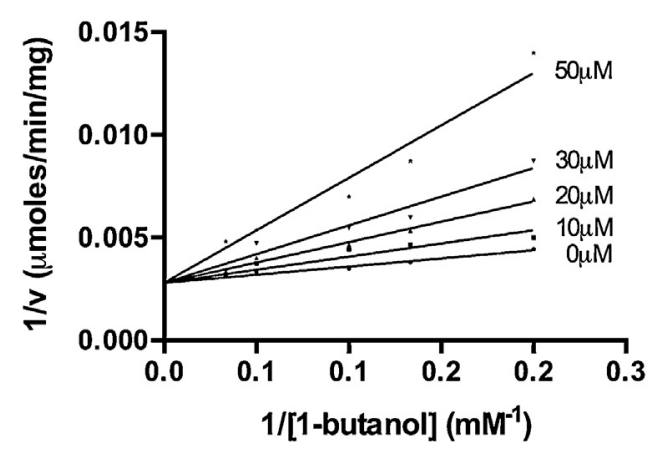

Fig. 4. Kinetics of pyrazole inhibition. Competitive inhibition plot for estimation of $K_{i}(10.05 \pm 0.03 \mu \mathrm{M})$ for pyrazole. Plot of reciprocal of rate $1 / x$ versus $1 / 1$-butanol concentration at increasing inhibitor concentrations (pyrazole). The concentrations of pyrazole employed were $0,10,20,30$ and $50 \mu \mathrm{M}$. Data points for individual lines were fitted to the Michaelis-Menten equation to estimate $k_{\mathrm{m}}$ (inset). The plot of the apparent $k_{\mathrm{m}}$ values against the pyrazole concentration was linear.

metabolism in the organism. This was explored by generating an isogenic mutant of HpSCADH. The mutant was generated by insertion of a kanamycin antibiotic resistance cassette within the coding region of the HpSCADH gene (Fig. 5).

H. pylori 1061 (wild type) and HpSCADH mutant strains were grown under standard microaerobic conditions in Brucella broth medium supplemented with FCS $(7 \%, v / v)$ at $\mathrm{pH} 7.0$. The optical density of the liquid cultures was monitored at $600 \mathrm{~nm}$ every $6 \mathrm{~h}$ over a period of $48 \mathrm{~h}$ (Fig. 6A). It is evident from the growth profiles that the HpSCADH mutant was compromised compared to the parental strain at $\mathrm{pH} 7.0$ suggesting a role for $\mathrm{HpSCADH}$ in the metabolism/growth of $H$. pylori. The growth of the isogenic mutant was even further compromised under acidic conditions (Fig. 6B). This finding was of particular interest since a previous report from this laboratory showed that $H$. pylori (HpAKR) played a role in acid adaptation (Cornally et al., 2008) it seems that the HpSCADH is somewhat similar. Growth characteristics at a $\mathrm{pH} 6.0$ for both the wild type and HpSCADH mutant strains were similar to those seen at $\mathrm{pH} 7.0$ (data not shown). The growth rate of both the wild type and the mutant were compromised at pH 5.0 (Fig. 6B). The growth rate of the HpSCADH mutant was severely compromised beyond $8 \mathrm{~h}$ of growth, compared to the wild type.

\subsection{Effect of pyrazole on the growth of wild type and HpSCADH negative mutant of $H$. pylori 1061}

In this study we have shown that pyrazole is an inhibitor of HpSCADH. It has also been shown that knockout of this enzyme causes growth inhibition of $H$. pylori (Fig. 6A). It was, therefore, of interest to assess the growth of this mutant $H$. pylori compared to the wild type, in the presence and absence of pyrazole.

The wild type $H$. pylori showed impaired growth in the presence of $20 \mu \mathrm{M}$ pyrazole similar to the HpSCADH mutant without pyrazole (Fig. 7). The growth of the HpSCADH mutant H. pylori was unaffected by the presence of the same concentration of pyrazole up to $22 \mathrm{~h}$ (Fig. 7). However, the mutant did show reduced growth after $22 \mathrm{~h}$

\section{Discussion}

\subsection{Sequence analysis}

HpSCADH showed high sequence identity to other putative short chain alcohol dehydrogenases from various bacterial pathogens. Its preference for $\mathrm{NAD}(\mathrm{H})$ over $\mathrm{NADP}(\mathrm{H})$ serves to group $\mathrm{HpSCADH}$ with other $\mathrm{NAD}(\mathrm{H})$ preferring SDRs such as $3 \alpha, 20 \beta$-hydroxysteroid dehydrogenase, $7 \alpha$-hydroxysteroid

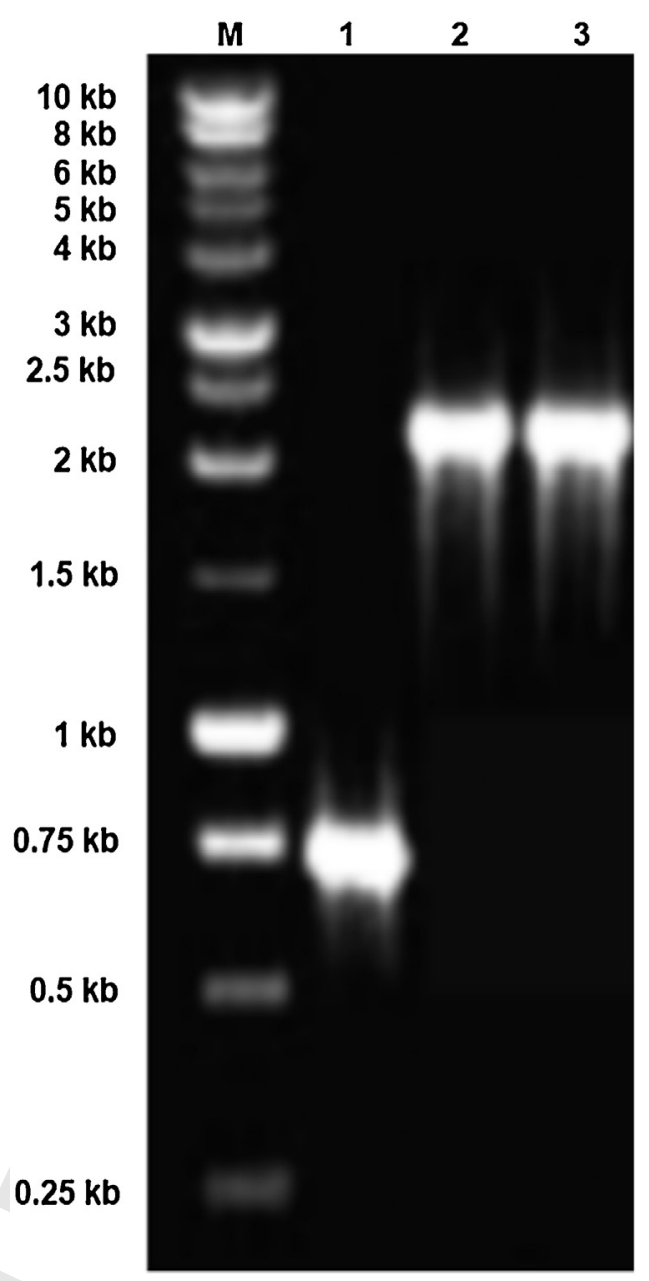

Fig. 5. Integration of the aphA-3 disrupted HpSCADH into the genome of $H$. pylori 1061. $0.8 \%$ agarose gel indicating the presence of the inserted aphA-3 cassette in the HpSCADH negative mutant of H.pylori 1061. Lanes 2 and 3 show a $1.5 \mathrm{~kb}$ increase in size of the HpSCADH gene (chromosomal) due to the presence of the inserted aphA3 cassette amplified from $H$. pylori 1061. Lane 1 contains the HpSCADH gene, with an approximate size of $750 \mathrm{bp}$, amplified from the parental wild type H. pylori 1061 Lane M contains the $1 \mathrm{~kb}$ DNA ladder (Promega). PCR was carried out as described in Section 2.

dehydrogenase, 2,3-dihydroxybiphenyl dehydrogenase, 2,3butanediol dehydrogenase, 3-hydroxyacyl-CoA dehydrogenase type 2 and dihydropteridine reductase that also have an acidic residue at position 36 . This acidic residue interacts with the $2^{\prime}$ and 3'-hydroxyl groups of the adenine ribose moiety in enzymes that are $\mathrm{NAD}(\mathrm{H})$-binding (Wierenga et al., 1985).

Sequence alignment studies with the sequence of highest identity showed that most of the conserved motifs of SDRs are found in the HpSCADH gene sequence.

\subsection{Substrate specificity}

Short-chain alcohol dehydrogenases/reductases (SDR) are a large superfamily of proteins with a large diversity of functions such as lipid, carbohydrate, amino acid or xenobiotic metabolism. HpSCADH has a clear preference for aliphatic alcohols. $k_{m}$ values were generally within $0.1-2 \mathrm{mM}$ for aldehyde substrates and 1-15 mM for alcohol substrates with the exception of 2-propanol, for which a higher $k_{\mathrm{m}}$ was obtained $(280 \mathrm{mM})$. HpSCADH showed no detectable activity towards range of aromatic alcohols aldehydes, dicarbonyls and ketones tested in this study. A discrete activity with cinnamaldehyde was observed for HpSCADH. This is 
(A)

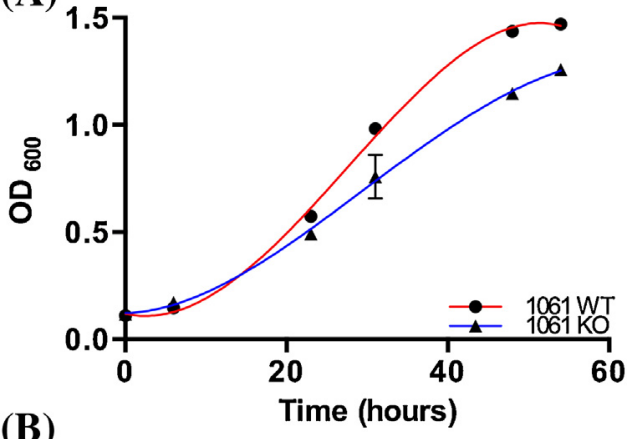

(B)

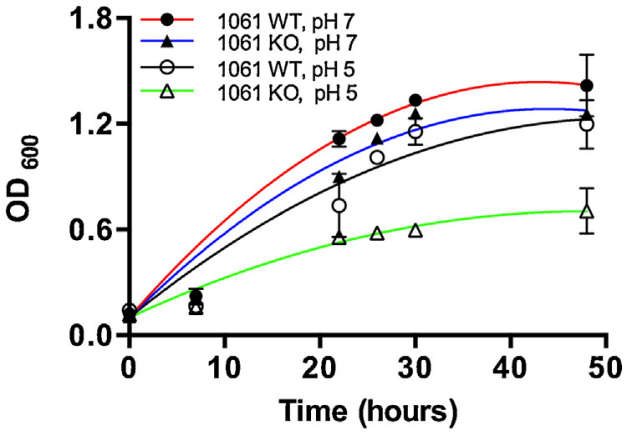

Fig. 6. Growth profiles of the isogenic HpSCADH negative mutants of $H$. pylori at neutral and acidic conditions. (A) The growth characteristics of both H. pylori 1061 wild type (red) and HpSCADH knockout mutant (blue) at $\mathrm{pH} 7.0$ in Brucella broth supplemented with $7 \%$ foetal calf serum and kanamycin $(20 \mu \mathrm{g} / \mathrm{ml})$. (B) The growth characteristics of both $H$. pylori 1061 wild type and HpSCADH mutant in Brucella broth supplemented with $7 \%$ foetal calf serum and kanamycin $(20 \mu \mathrm{g} / \mathrm{ml})$ at $\mathrm{pH} 7.0$ (control) and $\mathrm{pH}$ 5.0. All results are the mean \pm the SEM $(n=4)$. (For interpretation of the references to color in this figure legend, the reader is referred to the web version of the article.)
The substrate preference for HpSCADH overlaps somewhat with HpCAD which, despite its preference for cinnamaldehyde, will reduce aliphatic aldehydes (acetaldehyde, butyraldehyde and propionaldehyde) albeit poorly. It is worth noting that $\mathrm{HpSCADH}$ was capable of reducing pyridine aldehydes which may indicate that while it will oxidize aliphatic aldehydes entering the cell it may also have a specific role in an as yet unidentified metabolic processes.

While this study indicates that the organism is capable of producing a wide range of aldehydes by oxidation of the corresponding alcohol it is important to note that the reaction catalyzed by these enzymes is freely reversible and that the equilibrium for the reaction lies towards alcohol formation. Thus, it seems unlikely that such aldehydes could accumulate in the bacterium.

\subsection{Inhibition studies}

HpSCADH was found to be inhibited by various molecules (Table 3). By far the most significant inhibition was observed with pyrazole. This proved to be a potent competitive inhibitor of HPSCADH. While pyrazole is best known as an inhibitor of the medium-chain Zn containing alcohol dehydrogenases (see Shafqat $\mathbf{Q}^{3}$ et al., 1999) it has been shown to inhibit the Drosophila short chain alcohol dehydrogenase in a similar manner to the inhibition seen here for HpSCADH (Winberg et al., 1999).

The reduced growth profiles of the wild type $H$. pylori, in the presence of micromolar concentrations of pyrazole, suggest that this growth inhibitory effect is mediated through the inhibition of the HPSCADH enzyme.

Interestingly, Copeland et al. (2000) reported the synthesis of a class of pyrazole-based compounds that are amongst the most selective and potent inhibitors of $H$. pylori growth described to date. These compounds were designed to target dihydroorotate dehydrogenase (DHODase), an enzyme of the pyrimidine biosynthesis pathway of $H$. pylori. This raises the possibility that pyrazole and its derivatives might be combined to target both HpSCADH and DHODase. Since they target different pathways their growth inhibition might be expected to be additive. Further experiments are required to investigate this possibility. Nonetheless pyrazole inhibition may be useful as an adjunct to other measures to eradicate $H$. pylori since pyrazole has a long history of use in humans.

\subsection{Isogenic mutant}

Initially, it was believed that the ability of $H$. pylori to grow in an acidic environment was solely due to the activity of the urease enzyme. The ammonia generated from urease-mediated hydrolysis of urea was thought to neutralize stomach acid, at least in the microenvironment immediately surrounding the bacterium. However, a report in 2005 described the isolation of a urease-negative strain able to colonize the gastric mucosa suggesting other mechanisms are involved (Mine et al., 2005). Previously, we reported that HpAKR is required for optimum growth under acidic conditions (Cornally et al., 2008).

Here, we have characterized the HpSCADH negative isogenic mutant of $\mathrm{H}$. pylori in terms of growth at both neutral and acidic $\mathrm{pH}$. The data implies a role for HpSCADH in growth over extended periods under these conditions. Impairment of growth of the HPSCADH isogenic mutant may arise for a number of reasons. For example, loss of this enzyme may mean that the cell is unable to utilize specific nutrients or to metabolize toxic aldehydes. The process of acid adaptation is undoubtedly a complex process and must be effected quite quickly in order to colonize the gastric mucosa. It is possible that this process produces a number of alcohols or aldehydes that need to be metabolized rapidly. However, it is worth noting that growth was not completely halted indicating that compensatory mechanisms that overcome the loss of this
380

381 
enzyme are present presumably the other alcohol dehydrogenases of the cell.

When we examined the mutant under acid stress the difference in growth became more pronounced. The $\mathrm{pH}$ of the gastric mucosa is believed to vary between pH 4.0 and 6.5 (Bijlsma et al., 2002). Indeed, it has been suggested that $H$. pylori is exposed to the occasional acid shock as low as pH 2.0 (see Bijlsma et al., 2002; Schreiber et al., 2005). Lower pH studies were not pursued but it may be that this growth is even further compromised at pH values below 5.0.

For the HpAKR mutant previously studied in this laboratory, no difference in growth rate between the mutant and the wild type was seen at pH 7.0 (Cornally et al., 2008). At reduced pH (pH 5 and 5.5 ), the difference in the growth profiles of the wild type and the knockout of HpAKR (Cornally et al., 2008) were more dramatic than those observed for the HpSCADH mutant (this study). It is possible that both HpAKR and HpSCADH play a significant role in the longterm colonization of gastric mucosa. Bijlsma et al. (2000) showed that acid resistance in $H$. pylori is a complex function of a number of expressed proteins. The present data indicate that HpSCADH contributes to this process.

\section{Conclusion}

In conclusion, this work shows the Hp0357 gene product (HpSCADH) to be an active short chain alcohol dehydrogenase that differs in specificity from the other two oxidoreductases from $\mathrm{H}$. pylori in having single cofactor preference (NADH) and exhibiting a preference for aliphatic aldehydes. This work also assigns HpSCADH as a classical short chain alcohol dehydrogenase. Characterization of HpSCADH provides a more complete picture of all the aldehyde/alcohol metabolizing oxidoreductases present in $H$. pylori, demonstrating that a wide range of toxic aldehydes produced as a result of metabolism of dietary alcohols, can be efficiently reduced.

The isogenic HpSCADH negative mutant showed that under the conditions used in this study, HpSCADH is important for the growth of $H$. pylori. However, the knockout did not lead to complete inhibition of growth which implies that the function of this enzyme can be compensated by other enzymes, albeit less efficiently.

It would be of interest to determine whether the knockout of the HPAKR in conjunction with HPSCADH might be sufficient to halt growth of the organism i.e $e_{\lambda}$, whether the inhibitory effect seen with knockout of these enzymes is additive and sufficient to justify targeting these enzymes as potential therapeutics.

In recent studies, targeting the dihydroorotate dehydrogenase enzyme of the pyrimidine biosynthesis pathway (Copeland et al., 2000) has been pursued extensively as a means to inhibit $H$. pylori growth. Significantly, pyrazole is a known therapeutic with a history of use in humans while a number of AKR inhibitors have been developed for use in humans. It is possible that a combination of such existing alcohol dehydrogenase inhibiting compounds might be sufficient to prevent $H$. pylori colonisation of gastric mucosa. The advantage of such an approach is that the therapeutics for alcohol dehydrogenase inhibition is known compounds. In vivo tests are required to explore this notion further.

\section{Acknowledgement}

This work was supported by ABBEST research scholarship (to K.A.) from the Dublin Institute of Technology.

\section{References}

Bijlsma JJ, Lie-A-Ling M, Nootenboom IC, Vandenbroucke-Grauls CM, Kusters JG. Identification of the loci essential for growth of Helicobacter pylori under acidic conditions. Journal of Infectious Disease 2000;182:1566-9.
Bijlsma JJ, Waidner B, Vliet AH, Hughes NJ, Hag S, Bereswill S, et al. The Helicobacter pylori homologue of the ferric uptake regulator is involved in acid resistance. Infection and Immunity 2002;70:606-11.

Copeland RA, Marcinkeviciene J, Haque TS, Kopcho LM, Jiang W, Wang K, et al Helicobacter pylori-selective antibacterials based on inhibition of pyrimidine biosynthesis. Journal of Biological Chemistry 2000;27:33373-8.

Cornally D, Mee B, MacDonaill C, Tipton KF, Kelleher D, Windle HJ, et al. Aldo-keto reductase from Helicobacter pylori - role in adaptation to growth at acid $\mathrm{pH}$. FEBS Journal 2008;275:3041-50.

Figura N. Helicobacter pylori factors involved in the development of gastroduodenal mucosal damage and ulceration. Journal of Clinical Gastroenterology 1997;25(Suppl, 1):S149-63.

Filling C, Berndt KD, Benach J, Knapp S, Prozorovski T, Nordling E, et al. Critica residues for structure and catalysis in short-chain dehydrogenases/reductases (SDR). Journal of Biological Chemistry 2002;277:25677-84.

Goldberg L, Rydberg U. Inhibition of ethanol metabolism in vivo by administration of pyrazole. Biochemical Pharmacology 1969;18:1749-62.

Hinshelwood A, McGarvie G, Ellis EM. Characterisation of a novel mouse liver aldoketo reductase AKR7A5. FEBS Letters 2002;523:213-8.

Homann N, Jousimies-Somer H, Jokelainen K, Heine R, Salaspuro M. High acetaldehyde levels in saliva after ethanol consumption: methodological aspects and pathogenesis implications. Carcinogenesis 1997;18:1739-43.

Jornvall H, Hoog JO, Persson B. SDR and MDR: completed genome sequences show these protein families to be large, of old origin, and of complex nature. FEBS Letters 1999;445:261-4.

Kallberg Y, Opperman U, Jornvall H, Persson B. Short-chain dehydrogenase/reductase (SDRs): co-enzyme based functional assignments in completed genomes. European Journal of Biochemistry 2002;269:4409-17.

Krah A, Miehlke S, Pleissner KP, Zimmy-Arndt U, Kirsch C, Lehn N, et al Identification of candidate antigens for serologic detection of Helicobacter pylori-infected patients with gastric carcinoma. International Journal of Cancer 2004;108:456-63.

Kuhn A, Zyl C, Tonder AV, Prior BA. Purification and partial characterisation of an aldo-keto reductase from Saccharomyces cerevisiae. Applied and Environmental Microbiology 1995;61:1580-5.

Larroy C, Rosario FM, Gonzalez E, Peres X, Biosca JA. Properties and functional significance of a Sacchromyces cerevisiae ADHVI. European Journal of Biochemistry 2003;143-144:229-38.

Li TK, Theorell H. Human liver alcohol dehydrogenase: inhibition by pyrazole and pyrazole analogs. Acta Chemica Scandinavica 1969;23:892-902.

Matysiak-Budnik T, Karkkainen P, Methuen T, Roine RP, Salaspuro M. Inhibition of gastric cell proliferation by acetaldehyde. Journal of Pathology 1995;177:317-22.

Mee B, Kelleher D, Frias J, Malone R, Tipton KF, Henehan GTM, et al. Characterization of cinnamyl alcohol dehydrogenase of Helicobacter pylori, an aldehyde dismutating enzyme. FEBS Journal 2005;272:1255-64.

Mine T, Muraoka H, Saika T, Kobayashi I. Characteristics of a clinical isolate of ureasenegative Helicobacter pylori and its ability to induce gastric ulcers in Mongolian gerbils. Helicobacter 2005;10:125-31.

Parsonnet J, Friedman GD, Vandersteen DP, Chang Y, Vogelman JH, Orentreich N, et al. Helicobacter pylori infection and the risk of gastric carcinoma. New England Journal of Medicine 1991;325:1127-31.

Reynier M. Pyrazole inhibition and kinetic studies of ethanol and retinol oxidation catalyzed by rat liver alcohol dehydrogenase. Acta Chemical Scandinavica 1969;23:1119-29.

Salaspuro M. Alcohol consumption and cancer of the gastrointestinal tract. Best Practices \& Research Gastroenterology 2003;17:679-94.

Salaspuro M. Acetaldehyde and gastric cancer. Journal of Digestive Diseases 2011;12:51-9.

Salmela KS, Sillanaukee P, Itala L, Vakevainen S, Salaspuro M, Roine RP. Binding of acetaldehyde to rat gastric mucosa during ethanol oxidation. Journal of Laboratory Clinical Medicine 1997;129:627-33.

Sambrook JF, Maniatis EF. Molecular cloning. A laboratory manual. 2nd ed. Cold Spring Harbor, New York: Cold Spring Harbor Laboratory Press; 1989.

Schreiber S, Bucker R, Groll C, Azevedo-Vethacke M, Garten D, ScheidP, et al. Rapid loss of motility of Helicobacter pylori in the gastric lumen in vivo. Infection and Immunity 2005;73:1584-9.

Shafqat J, Hoog JO, Hjelmqvist L, Oppermann UCT, Ibanez C, Jornvall H. An ethanol-inducible MDR ethanol dehydrogenase/acetaldehyde reductase in Escherichia coli. European Journal of Biochemistry 1999:305-11.

Smeets LC, Bijlsma JE, Boomkens SY, Vandenbroucke-Grauls CM, Kusters JG. comH a novel gene essential for natural transformation of Helicobacter pylori. Journal of Bacteriology 2000;182:3948-54.

Tanaka N, Nonaka T, Nakanishi M, Deyashiki Y, Hara A, Mitsui Y. Crystal structure of the ternary complex of mouse lung carbonyl reductase at $1.8 \AA$ resolution: the structural origin of coenzyme specificity in the short-chain dehydrogenase/reductase family. Structure 1996;4:33-45.

Todaka T, Yamano S, Toki S. Purification and characterisation of NAD-dependent morphine-6-dehydrogenase from hamster liver cytosol, a new member of the aldo-keto reductase superfamily. Archives of Biochemistry and Biophysics 2000;374:189-97.

Tomb JF, White O, Kerlavage AR, Clayton RA, Sutton GG, Fleischmann RD, et al. The complete genome sequence of the gastric pathogen Helicobacter pylori. Nature 1997;388:539-47.

Van der Oost J, Voorhorst WGB, Kengen SWM, Geerlng ACM, Wittenhorst V, Gueguen $\mathrm{Y}$, et al. Genetic and biochemical characterisation of a short chain alcohol 
dehydrogenase from the hyperthermophilliv archaeon Pyrococcus furiosus. European Journal of Biochemistry 2001;268:3062-8.

Von Herbay A, Schreiter H, Rudi J. Simultaneous gastric adenocarcinoma and MALT-type lymphoma in Helicobacter pylori infection. Virchows Archiv 1995;427:445-50.

Wierenga RK, Maeyer MC, Hol WG. Interaction of pyrophosphate moieties with $\alpha-$ helices in dinucleotide binding proteins. Biochemistry 1985;24:1346-57.
Wierenga RK, Terpstra P, Hol WG. Prediction of the occurrence of the ADP-binding beta alpha beta-fold in proteins, using an amino acid sequence fingerprint. Journal of Molecular Biology 1986;187:101-7.

Winberg JO, Michelle Kaaber Brendskag KM, Sylte I, Lindstad RI, McKinley-McKee JS. The catalytic triad in Drosophila alcohol dehydrogenase: $\mathrm{pH}$, temperature and molecular modelling studies. Journal of Molecular Biology 1999:601-16. 